\title{
The High Country Environment
}

The most important environmental factors influencing farming and the choice of pasture species are:

- Temperature

- Soil moisture

- Soil fertility

- Pasture management.

Temperature and moisture gradients define the general pattern of soils, original vegetation and present farming systems within New Zealand (Figure 1). With decreasing moisture and temperature, pasture production falls, so pasture yields in the high country are generally much lower than elsewhere. The traditionally large size of both paddocks and runs in the high country was related to the low level of pasture yield from native vegetation.

\section{Temperature}

Temperature is a fundamental factor determining potential pasture production and choice of species, so the farming system must be adapted to the natural conditions. Temperature cannot be modified. The high country is characterised by having the lowest mean temperatures, greatest extremes and widest ranges of variation in mean monthly temperature than elsewhere in New Zealand. The annual range is up to $14^{\circ} \mathrm{C}$ in some inland high country basins, compared with $8^{\circ} \mathrm{C}$ in coastal areas. The New Zealand average is $10^{\circ} \mathrm{C}$.
Local temperature characteristics (means and seasonal ranges) are greatly influenced by altitude, aspect and slope. The high country is on the coldest margin of New Zealand agriculture, for both mean and seasonal temperature, and has the greatest variation with aspect. Even in the lower altitude inland basins there is a period of at least five months when there is little or no pasture growth. Frosts may occur in all seasons, although summer temperatures are good for pasture growth. Because of the temperature differential, and the effect of soil moisture, there may be extreme differences between sunny and shady aspects.

In choosing species for the high country, those which grow at lower temperatures should be preferred. Grasses generally have greater growth at lower temperatures than legumes, although this has not been investigated. For example, winter and spring temperatures are generally too low for adequate growth of subterranean clover in the high country, yet cocksfoot has a long growing season.

Lower temperatures and large annual variation also mean a higher frequency of frost which, in the high country, can occur throughout the year. Frost tolerance is an important characteristic of pasture species, with the grasses generally being more tolerant than legumes. Legumes and grasses are both vulnerable at the seedling stage because they are in the more intense frost zone near ground level and may also be in more open stands. Mature stands of grasses and legumes

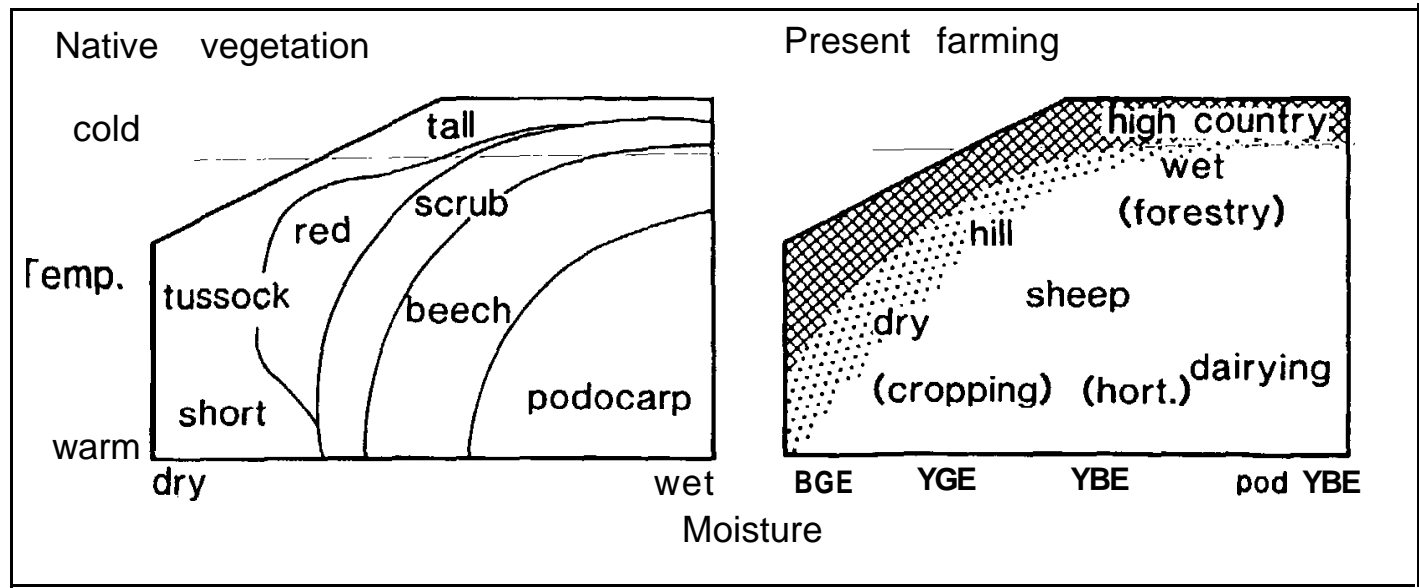

Figure 1: Distribution of original vegetation and present farming practices in New Zealand in relation to the environment gradients of temperature and moisture. The high country is indicated by cross hatching and the hill country by dots. 
may be less susceptible to frost damage when there is a large bulk of herbage. However, in this state lucerne, white clover and lotus are all susceptible to foliar frost damage. Alsike clover and tetraploid red clover are more tolerant of winter frost.

The most frost tolerant grasses, in terms of plant survival when mature, are tall fescue, and cocksfoot, followed by ryegrasses, timothy, bromes and phalaris. Species also differ in the extent to which foliage bum-off occurs following frosting. For example, cocksfoot bums off at the tips even though its total bulk is still generally greater than other species. Complete winter kill of plants is not common, though it occurs in white clover and ryegrass in some years, and in some plants from a wide number of species in very cold winters.

Because of the winter no-growth period, saved pasture is needed. Desirable species for this purpose are those which are capable of good autumn growth, are palatable in the rank state, and suffer a minima1 loss of feed quality following frosting. Species differ in these attributes. For example, cocksfoot grows well in autumn, is frost-tolerant, but of lower palatability; bromes are palatable but grow poorly in autumn; and ryegrasses produce moderate autumn growth, are highly palatable but relatively intolerant of frost.

\section{Soil Moisture}

Moisture is also a fundamental factor controlling potential production, and one which cannot be modified from the natural distribution pattern except, in special cases, by irrigation and drainage. The choice of suitable pasture species is heavily dependent upon soil moisture, which covers a very wide range from the high rainfall areas in the western ranges to the low rainfall in the inland basins. Consequently a wide range of pasture species is required - from those that survive the wet (and frequently colder) conditions of high altitude, to extremes of drought on sunny faces in the inland basins. The amount of soil moisture available for growth also depends on local factors such as altitude, slope and aspect, and on the moisture retention characteristics of the soil.

While the proportion of the high country under irrigation may never be large relative to its total area, it can be very important for filling shortages in critical animal feed periods. Irrigation response will be larger in the low rainfall area and have the effect of changing a site to a moister part of the environmental gradient, though retaining the beneficial effect of higher soil fertility and warmer temperatures often associated with drier zones. Irrigation is also important in taking the risk out of farming in drought-prone areas and in guaranteeing winter feed supply, and this will affect the choice of suitable pasture species.

\section{Patterns Of Soil Distribution}

The effects of temperature and moisture interact to produce the range of sites of differing potential pasture production that can be seen in any run or landscape. The high country, and its farming options, has to be seen in the perspective of the total variation within the New Zealand environment (Figure 1). Because temperature and moisture are such important limitations on pasture production, the farming options in the high country are severely constrained by its climate.

The effects of climate are reflected in the soils, so that the interactions between moisture and temperature result in a characteristic pattern of soil types. This is because the breakdown of soil minerals, to release nutrients by weathering, generally increases with temperature, while the loss of nutrients by downward washing through the soil by leaching increases with rainfall. Thus the distribution of soils is related to these topographic variations in temperature and moisture regimes (Figure 2a).

The major soil types are described by the colour of the subsoils, and these show the balance of weathering and leaching. Four major soil groups occur in the high country.

Brown-grey earths (BGE) are weakly weathered and leached because they occur at low altitude in the semi-arid basin areas of Central Otago, the Mackenzie Basin and the upper Waitaki Valley. Pre-European native vegetation was short tussock grassland. Pasture production is severely limited by moisture deficiency.

Yellow-grey earths (YGE) often occur on fans and lower slopes within the high country, and carry short tussock grassland with fescue and some silver tussock. They are more leached than the brown-grey earths. Pasture production is less limited by moisture shortage than on the brown-grey earths.

Upland high country yellow-brown earths (YBE) occur on higher slopes and plateau areas in inland mountain ranges and with increased altitude and rainfall are progressively more leached. 
(a)

Soils in relation

to climate

(b)

Landscape units in part of the soil range
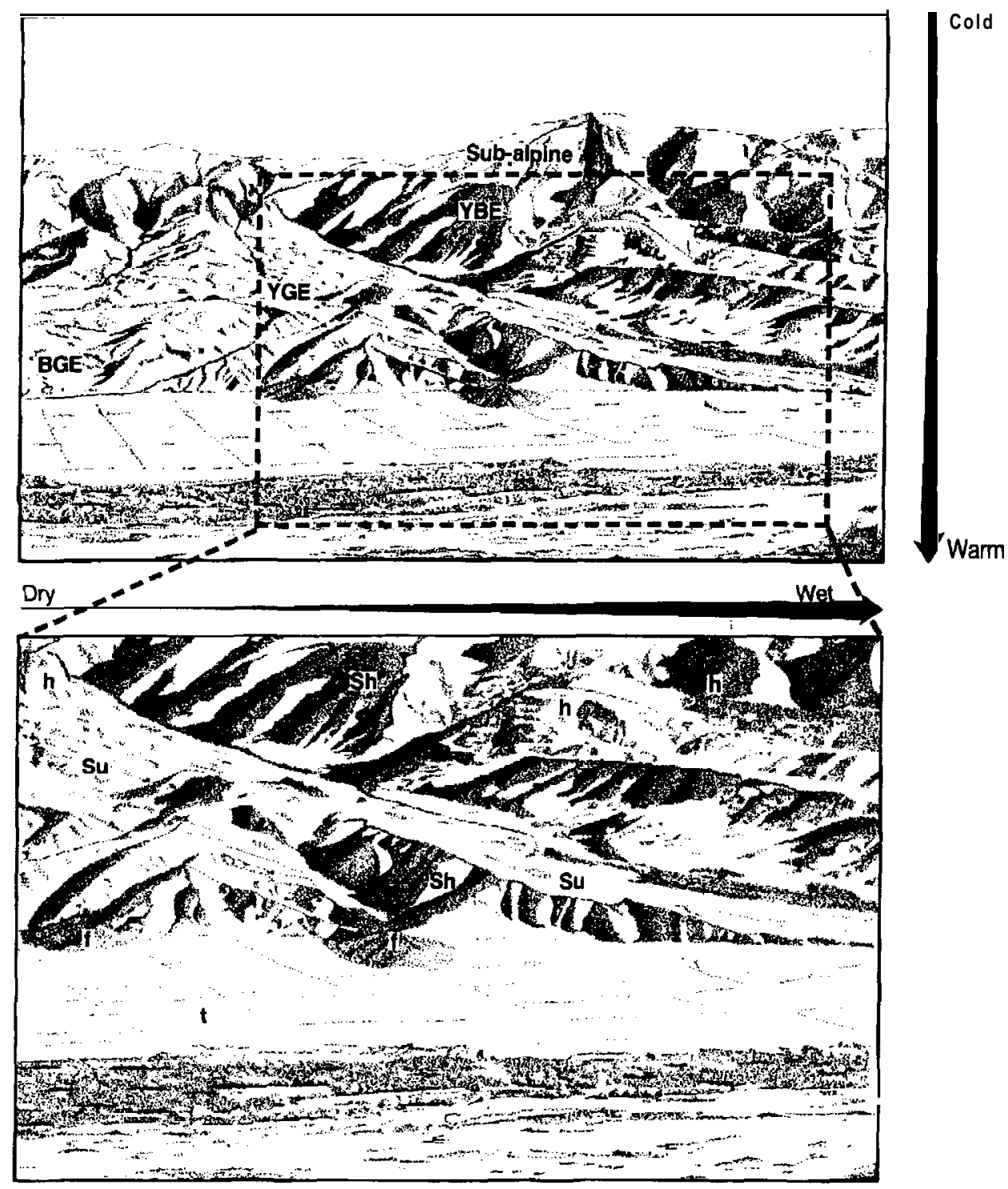

(c)

Subdivision into farm

management units.

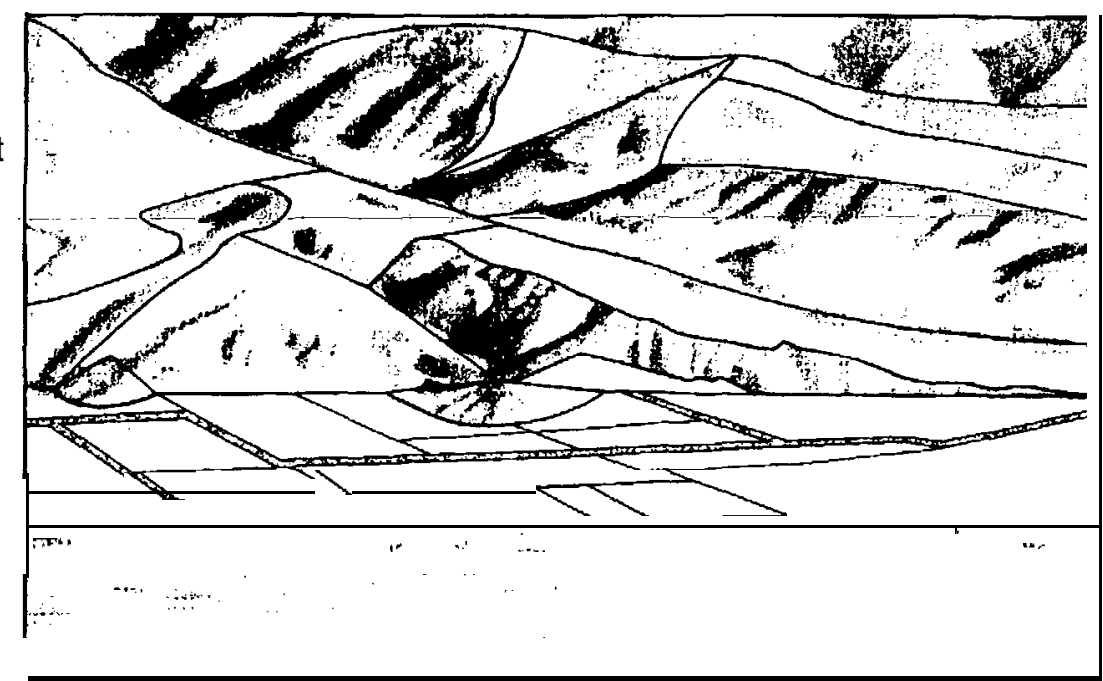

Figure 2: Subdivision of a generalised high country scene according to environmental gradients. 
As the release of nutrients by weathering is also slowed down by decreasing temperatures at higher altitudes, soils are increasingly subject to more severe nutrient deficiencies. They characteristically carry tussock grassland species, with greater dominance of snowgrass on the high country soils. On the lower slopes potential pasture production increases with rainfall and altitude but, because of decreasing temperature, the potential production decreases with further increase in elevation in this soil group

Upland and high country podzolised yellowbrown earths (pod YBE) and podzols are even more strongly leached than the yellow-brown earths. They occur in the higher and wetter areas and grade into the alpine soils of the mountains. The term podzolised refers to the effects of very strong leaching in these groups of soils, with the appearance of a pale layer between the top soil and the yellow-brown subsoil. These soils have very low potential for pastoral agriculture because they suffer from severe nutrient deficiencies as a consequence of the high rainfall and strong leaching, and because lower temperatures at these higher altitudes also restrict pasture growth.

\section{Soil Fertility}

plant growth in high country soils. In addition, selenium and, maybe, iodine and sodium will be required for animal health. Adequate calcium levels are required to maintain general soil structure and nutrient exchange characteristics.

The distribution of nutrient deficiencies is not random, but is closely related to the processes of leaching and weathering, and the soil pattern described in the previous section.

The pattern illustrated in Figure 3 shows that, in the semi-arid zone, brown-grey earths usually have sufficient phosphorus and molybdenum, but the topsoils are severely deficient in sulphur. Some deep-rooting plants, like luceme, may be able to use sulphur from the subsoil. Deficiencies of sulphur and phosphorus occur in

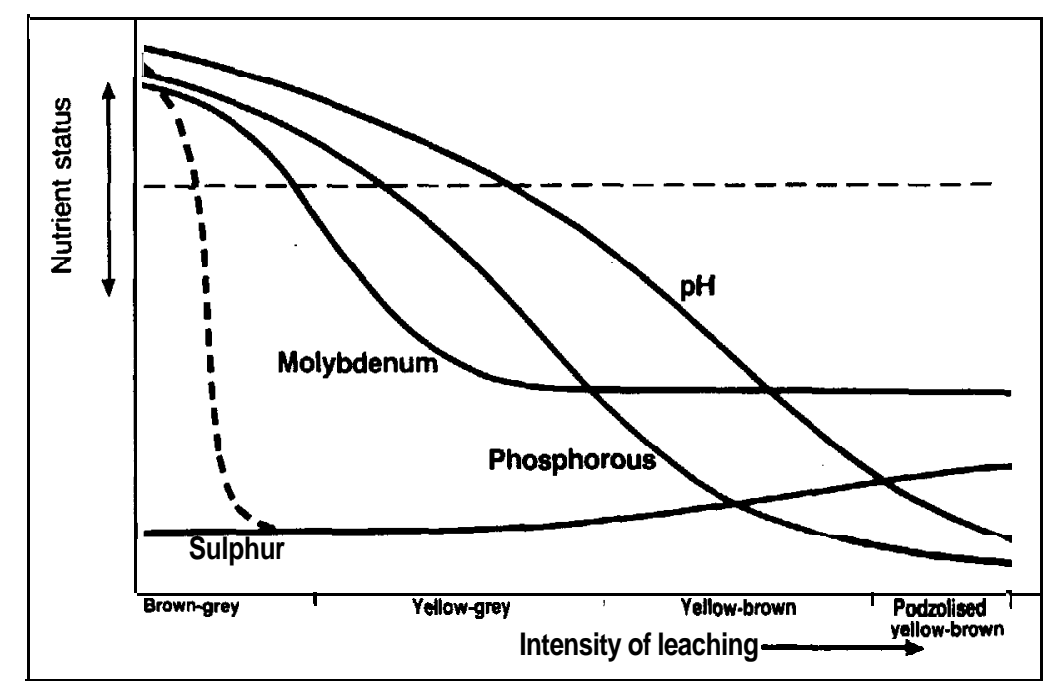

Figure 3: Soils, nutrient status and fertiliser requirements for a series of high country soils is related to rainfall and/or leaching.
While temperature and soil moisture have a profound effect on farming options and choice of species, they are generally uncontrollable. The third factor, soil fertility, is the one which, in practice, can be most easily modified - either by the selection of areas of different natural fertility, or by the addition of fertiliser.

The nutrient element which most severely limits pasture production is nitrogen, and it is deficient in most soils. In New Zealand the nitrogen deficiency is usually overcome by growing legumes which, through associated rhizobia in root nodules, fix nitrogen from the air. It is therefore important to satisfy the nutrient requirements of introduced legumes for good pasture production.

Sulphur, phosphorus and molybdenum are the nutrients most commonly deficient for legume yellow-grey earths, and are usually more severe in yellow-brown earths, because these soils are progressively more impoverished by the increasing intensity of leaching. For the same reason, soil acidity also becomes an increasing problem in the most strongly leached soils in the higher and wetter areas. The podzolised soils are so severely leached that their nutrient status is very low and they are strongly acid. Molybdenum deficiency is widespread in yellow-grey and yellow-brown earths, except where rainfall is below $550 \mathrm{~mm}$ per year.

This general pattern of soil nutrient status can sometimes be changed by natural factors such as soil rejuvenation by erosion or deposition, and non-uniformity of underlying rock type. Once the land is developed agriculturally, the pattern is further distorted by previous fertiliser 
applications and nutrient redistribution by stock. Such local variations can be detected by soil testing.

Deficiencies can be corrected by the application of fertilisers to develop and maintain productive pasture. The amounts required are generally related to the soil pattern, and should be greater for initial development than for subsequent maintenance.

Generalised recommendations are given in Table 1, which relates fertiliser rates to the characteristics of each of the four major soil

Table 1: $\quad$ Characteristics of typical high country soils.

\begin{tabular}{|c|c|c|c|c|}
\hline & $\begin{array}{c}\text { Brown- } \\
\text { grey } \\
\text { Earths }\end{array}$ & $\begin{array}{l}\text { Yellow- } \\
\text { grey } \\
\text { Earths }\end{array}$ & $\begin{array}{l}\text { Yellow- } \\
\text { brown } \\
\text { Earths }\end{array}$ & $\begin{array}{c}\text { Podzolised } \\
\text { yellow- } \\
\text { brown } \\
\text { Earths }\end{array}$ \\
\hline $\begin{array}{ll}\text { Intensity } & \text { of } \\
\text { leaching } & \end{array}$ & Low & $\begin{array}{l}\text { Low- } \\
\text { medium }\end{array}$ & $\begin{array}{l}\text { Medium- } \\
\text { High }\end{array}$ & Very High \\
\hline $\mathrm{pH}$ & High & Medium & Low & Very Low \\
\hline & $(>6.0)$ & $(5.2-6.0)$ & $(4.6-5.2)$ & $(<4.6)$ \\
\hline Sulphur status & Low * & Low & Low & Low \\
\hline $\begin{array}{l}\text { Phosphorus } \\
\text { status }\end{array}$ & High & Medium & Low & Low \\
\hline $\begin{array}{l}\text { Molybdenum } \\
\text { status }\end{array}$ & Adequate & Deficient & Deficient & Deficient \\
\hline $\begin{array}{l}\text { Optimal } \\
\text { fertiliser at } \\
\text { present }\end{array}$ & $\begin{array}{l}\text { Sulphur } \\
\text { super extra } \\
(27 \% \mathrm{~S})\end{array}$ & $\begin{array}{l}\text { Sulphur } \\
\text { super or } \\
\text { RPR + S }\end{array}$ & $\begin{array}{l}\text { Super } * * \text { or } \\
\mathrm{RPR}+\mathrm{S}\end{array}$ & Uneconomic \\
\hline $\begin{array}{l}\text { Establishment } \\
\text { fertiliser rate }\end{array}$ & $\begin{array}{l}200 \mathrm{~kg} / \mathrm{ha} \\
\text { sulphur } \\
\text { super }\end{array}$ & $\begin{array}{l}200 \mathrm{~kg} / \mathrm{ha} \\
\text { Mo sulphur } \\
\text { super }\end{array}$ & $\begin{array}{l}250 \mathrm{~kg} / \mathrm{ha} \\
\text { Mo super }\end{array}$ & Uneconomic \\
\hline $\begin{array}{l}\text { Maintenance } \\
\text { fertiliser rate }\end{array}$ & $\begin{array}{l}200 \mathrm{~kg} / \mathrm{ha} \\
\text { sulphur } \\
\text { super extra } \\
\text { every 3-4 } \\
\text { years }\end{array}$ & $\begin{array}{l}200 \mathrm{~kg} / \mathrm{ha} \\
\text { sulphur } \\
\text { super every } \\
2-3 \text { years }\end{array}$ & $\begin{array}{c}250 \mathrm{~kg} / \mathrm{ha} \\
\text { super every } \\
2-3 \text { years }\end{array}$ & Uneconomic \\
\hline
\end{tabular}

areas where these soils are found. Molybdenised fertiliser is recommended for initial pasture establishment on soils where molybdenum is likely to be deficient, and it should be used for maintenance about once every four years. Liming is discussed later under the heading Inoculation and coating in the section on pasture establishment.

A different approach to calculating maintenance rates, which allows for the differences in production, utilisation and stocking rate on contrasting soil types, is to allow $25 \mathrm{~kg} / \mathrm{ha} / \mathrm{yr}$ superphosphate for each stock unit. This approach more closely approaches the sustainability concept that fertiliser rate must replace the wool and meat removed.

Both approaches are generalisations and do not allow' for the local variations in soil nutrient status which were described earlier.

Good recommendations come from direct soil testing made at regular intervals to determine trends.

Soil tests for $\mathrm{P}, \mathrm{S}$ and $\mathrm{pH}$ have proved to be good indicators of responses to initial applications of fertilisers in tussock grassland development.

Soil sampling and testing should therefore always be, carried out before a large development programme is started and -regularly- thereafter-formaintenance purposes. groups. It should be noted that the proportion of sulphur is highest in the fertilisers recommended for the brown-grey earths and that the proportion of phosphorus increases in the fertilisers recommended for those soils where phosphorus deficiency becomes more severe. The podzolised soils are considered uneconomic to develop because of the large amounts of fertiliser required to overcome their natural deficiencies, and because potential pasture production is severely limited by climate in the
Separate samples should be taken for each distinct area of land which differs in terms of soil type, aspect, slope, vegetation or previous land use, and for which a particular fertiliser treatment could conveniently be applied.

On the moister yellow-grey earths (rainfall $>550 \mathrm{~mm}$ ), or where soil $\mathrm{pH}$ is $<5.5$, reactive phosphate rock (RPR) is a cheaper phosphate option. Suppliers offer suitable RPR+S mixtures which supply phosphorus and sulphur 
in the correct proportion to suit farming on yellow-grey and yellow-brown earths.

Escalating costs of superphosphate, transport and application have triggered a move to high analysis phosphorus fertilisers such as ammonium phosphate, triple superphosphate, reactive phosphate rock, and the same rock partially acidulated with phosphoric acid. All of these contain little or no sulphur and will need to be supplemented with sulphur.
(Figure 4 lower right). In warm, but drier conditions there is increasing depression of summer pasture growth and hence feed supply though still with the potential of winter growth (Figure 4 lower left). By contrast, as altitude increases and temperature decreases, the potential for this winter growth decreases. Thus in parts of the high country, there is a nongrowth period of five months or more, and standing herbage for the winter has to be carried forward from the previous summer and autumn.

Mixtures of elemental sulphur and sodium bentonite offer the possibility of preparing fertilisers to suit different environments, both with respect to proportions of sulphur and phosphorus, and with different degrees of reactivity. Unfortunately; the high cost of their manufacture has, in the meantime, precluded the commercial development of such mixtures by New Zealand fertiliser manufacturers. Manufacturers are now offering instead a greater range of superphosphates enriched with greater quantities of elemental sulphur as standard products, as well as fertiliser mixtures customised to individual client requirements when possible.

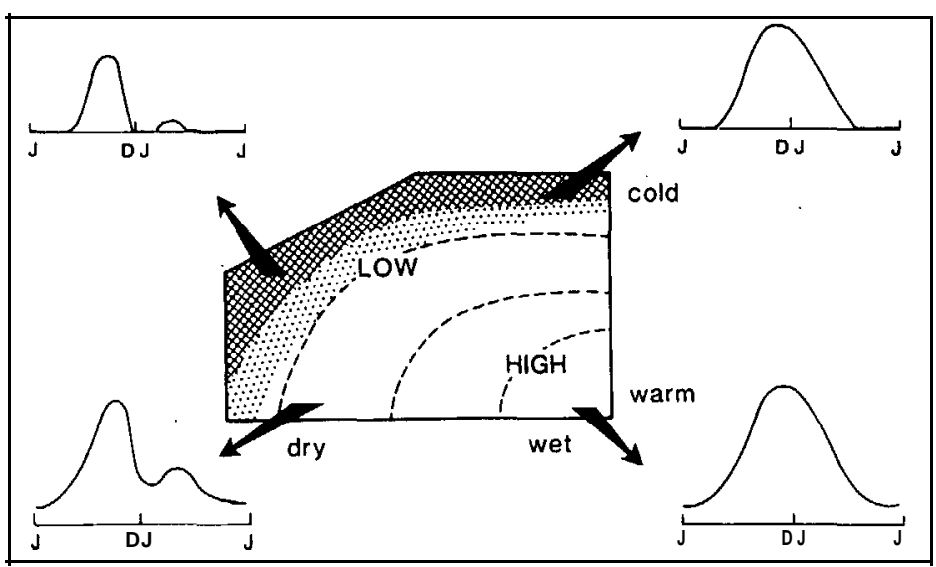

There will also be an increasing role for nitrogen fertiliser to increase the initial establishment of grasses, and for special purpose winter grass paddocks.

The genera1 effect of fertiliser application, legume nitrogen fixation and mineral removal will be for the soil to become more acid. One of the trends in pasture evaluation work is to find species which retain their productivity and sustainability in the more acid conditions.

\section{Potential Pasture Production}

Variations in temperature and moisture are important in determining the variability of pasture productivity in two ways. Firstly, they will influence the potential productivity, which is greatest in the moist, warm environments and least in the dry cold areas (Figure 4). Secondly, the variation in temperature and moisture will influence the seasonal distribution of potential pasture growth.

In the warm, moist environment enjoyed by much of New Zealand, growth can occur in all seasons, being greatest in spring and summer

By world agricultural standards, New Zealand is not particularly cold, hot, wet or arid but fluctuations towards these four extremes seem to occur in a matter of days or weeks.

An overview of plant production and breeding of pasture plants for New Zealand would suggest that the species which suit the New Zealand environment, are those which can tolerate, and make an adequate growth contribution under a range of intermediate conditions without having a tendency to go into long term dormancy when they encounter brief periods of adverse temperature or moisture conditions.

Given estimates of the three environmental variables of temperature, moisture and fertility, it is possible to make reasonable estimates of the potential annual average pasture production levels.

This is shown in Figure 5 for three different soil fertility levels (low, moderate and high) and for the same range of temperatures and moisture as in Figure 4. 


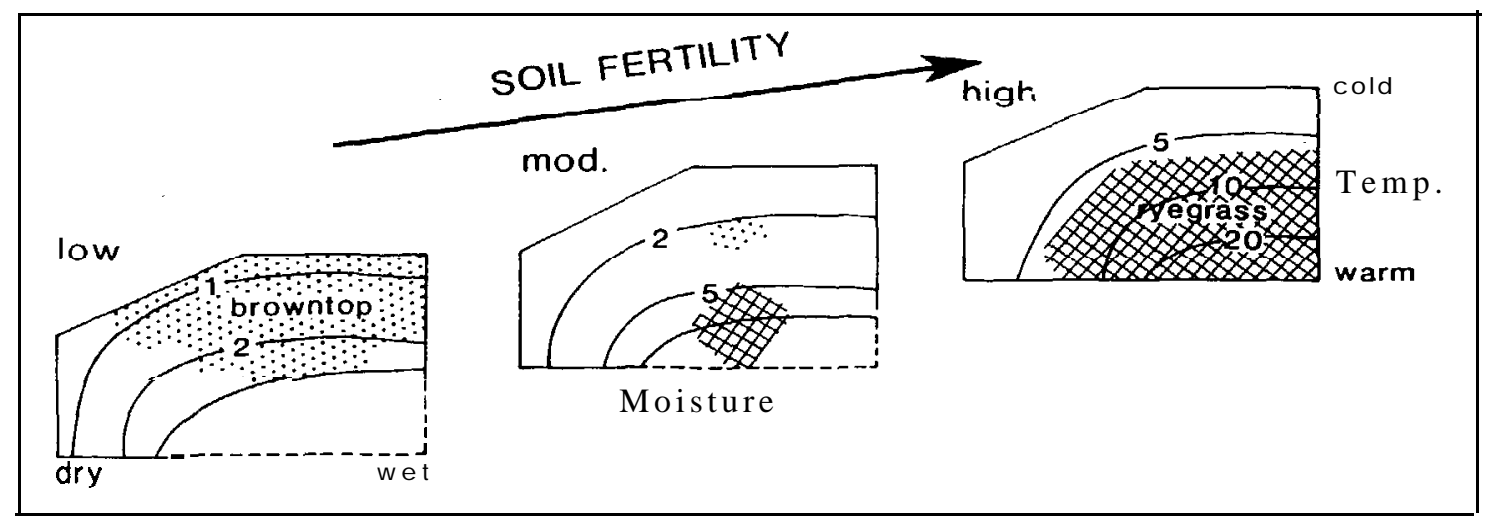

Figure 5: Estimated potential annual pasture yields (t DM/ha/year) in relation to temperature, moisture and three levels of soil fertility. Ranges of temperature and moisture are the same as earlier diagrams. The best zones for two grasses, browntop and perennial ryegrass, are indicated.

The high country will again be represented along the left and upper boundary of each diagram.

Figure 5 illustrates four important points.

- There is a rapid fall-off in potential pasture production as temperatures decrease with altitude and aspect. This decrease is exponential rather than linear.

- Similarly, there is a rapid fall-off in potential pasture production as rainfall and soil moisture decrease; again, it is exponential rather than linear.

- If a site with particular moisture and temperature conditions is transformed from its natural low fertility state to a high fertility state then, in the high country situation, there is about a fivefold increase in potential pasture production.

- If the other input, irrigation, is used it moves a site from the dry to the wet end of the gradient. Responses of potential annual pasture production to water_ are not large, probably only two-fold. In any irrigation development, both water and fertiliser are applied, to give the often ten-fold increase in potential production.

These potential ten-fold increases mean suitable sites in the high country have a strong capability for production of winter feed and special purpose pastures.

However, species differ in their environmental needs and tolerances. Our belief is that, while Figure 5 estimates the potential pasture productivity and the general pattern for all species, only one or two species reach the full potential of a particular site as determined by the particular combination of temperature, moisture and fertility.

For example, browntop is probably the grass best adapted to low fertility set stocked sites of moderate temperature and moisture, just as perennial ryegrass is one of the best grass species for high fertility, warm, moderately moist sites.

It is also true that each pasture species can perform adequately in a wide range of conditions, however, the most appropriate place for each of a whole range of species is considered in detail in later sections of the publication. 